\title{
Understanding the impacts of a combination of service improvement strategies on bus running time and passenger's perception
}

\author{
Ehab I. Diab \\ Ph.D. student \\ School of Urban Planning \\ McGill University \\ Suite 400, 815 Sherbrooke St. W. \\ Montréal, Québec, H3A 2K6 \\ Canada \\ Tel.: 514-549-0093 \\ Fax: 514-398-8376 \\ E-mail: ehab.diab@mail.mcgill.ca \\ Ahmed M. El-Geneidy \\ Assistant Professor \\ School of Urban Planning \\ McGill University \\ Suite 400, 815 Sherbrooke St. W. \\ Montréal, Québec, H3A 2K6 \\ Canada \\ Tel.: 514-398-8741 \\ Fax: 514-398-8376 \\ E-mail: ahmed.elgeneidy@mcgill.ca
}

November 2011

Word Count 4649, 2 Figure, and 5 Tables

For references please use: Diab, E. \& El-Geneidy, A. (2012). Understanding the impacts of a combination of service improvement strategies on bus running time and passenger's perception. Transportation Research Part A: Policy and Practice, 46(3), 614-625. 


\title{
Research Highlights
}

1- $\quad$ This article aims to evaluate the impact of implementing a combination of service improvement strategies including using smart card fare collection, introducing limited-stop bus service, implementing reserved bus lanes, using articulated buses, and implementing transit signal priority (TSP).

2- $\quad$ The combination of these strategies has lead to a $10.5 \%$ decline in running time along the limited stop service compared to the regular service.

3- $\quad$ Riders are generally satisfied with the service improvements. They tend to overestimate the savings associated with the implementation of this combination of strategies by 3.5 to 6.0 minutes and by 2.5 to 4.1 minutes for both the regular route and the limited stop service, respectively.

4- $\quad$ This study helps transit planners and policy makers better understand the effects of implementing a combination of strategies to improve running time and passenger's perception of satisfaction.

\begin{abstract}
Transit agencies implement many strategies in order to provide an attractive transportation service. This article aims to evaluate the impacts of implementing a combination of strategies, designed to improve the bus transit service, on running time and passenger satisfaction. These strategies include using smart card fare collection, introducing limited-stop bus service, implementing reserved bus lanes, using articulated buses, and implementing transit signal priority (TSP). This study uses stop-level data collected from the Société de transport de Montréal (STM)'s automatic vehicle location (AVL) and automatic passenger count (APC) systems, in Montréal, Canada. The combination of these strategies has lead to a $10.5 \%$ decline in running time along the limited stop service compared to the regular service. The regular route running time has increased by $1 \%$ on average compared to the initial time period. The study also shows that riders are generally satisfied with the service improvements. They tend to overestimate the savings associated with the implementation of this combination of strategies by 3.5 to 6.0 minutes and by 2.5 to 4.1 minutes for both the regular route and the limited stop service, respectively. This study helps transit planners and policy makers to better understand the effects of implementing a combination of strategies to improve running time and passenger's perception of these changes in service.
\end{abstract}

Keywords: running time, limited-stop bus service, articulated buses, reserved lane, smart card fare collection, transit signal priority (TSP), passenger perception 


\section{INTRODUCTION}

Boulevard Saint-Michel is a heavily used bus corridor located to the east of Montréal's central business district, in the province of Québec, Canada. According to official estimations this corridor serves around 43,000 passengers per day. This service is operated by the Société de Transport de Montréal (STM), the transit provider on the island of Montréal, and moves more than 1.2 million rides per weekday on its 4 metro lines and 202 bus routes. In an attempt to improve transit service on the island, STM has implemented a series of measures. These measures included implementation of a smart card system called 'OPUS' on April, 2008, to provide passengers with the attractiveness and advantages of automated fare collection (Société de transport de Montréal, 2010). At the same time, the STM made the decision to implement a limited-stop bus service (Route 467) running parallel to the regular bus service (Route 67) along the Boulevard Saint-Michel corridor. On March 30 ${ }^{\text {th }}$, 2009, the STM implemented this new service. The new route serves only $40 \%$ of the stops along Route 67 , with an average stop spacing of 615 meters. Route 467 runs on weekdays from 6:00 A.M. to 7:00 P.M. with an average headway of 10 minutes and 7 minutes during peak hours. Starting August $3^{\text {rd }}, 2009$, the STM began to operate a reserved bus lane during peak hours in order to improve the service. On February $1^{\text {st }}, 2010$, the STM continued its series of improvements along the corridor by assigning a number of articulated buses to serve Route 467. Finally, on September $1^{\text {st }}, 2010$, the STM equipped a few of these buses with transit signal priority (TSP) systems which operates across all signalized intersections along the corridor. Figure 1 is a timeline showing the modifications applied to the studied routes between January 2007 and April 2011.

This article aims at evaluating the impacts of this combination of measures implemented by STM on bus running time and passenger's perception of these changes in service. This is done through analyzing archived AVL/ APC data for Routes 67 and 467 and conducting on-site surveys to measure the perceptions of passengers using these two routes. The paper starts with a literature review of bus running time, limited-stop service, smart card use, exclusive bus ways, articulated buses, and TSP systems. This is followed by a description of the studied route. The next section pertains to the methodology used to prepare and analyze the data for running time and survey questions. This is then followed by a discussion of those results, and wraps up with a reiteration of the main conclusions..

\section{LITERATURE REVIEW}

Transit users consider the service reliable when their in-vehicle time (i.e. running time), access and egress time (Hensher et al., 2003; Murray and Wu, 2003), and their waiting time at stops are minimized. Reduction in running time is expected to increase ridership and rider satisfaction (Hensher et al., 2003). Running time is the time that takes a bus to move between two defined points during a trip along a specific route. The review of previous studies in transit literature identified several common factors that influence running time. These factors include passenger activity, load, distance, delay at the beginning of the trip, period of the day, number of actual stops made, weather and traffic conditions (Abkowitz and Engelstein, 1983; Levinson, 1983; Strathman et al., 2000). Transit agencies generally try to reduce the effect of these factors and enhance the quality of service by adopting different strategies. These strategies are determined according to the project location, funding and required improvements. Strategies may 
include smart card fare collection systems, reserved bus lanes, limited bus stop service, articulated buses, and TSP systems. Nevertheless, a direct method to evaluate the success of these strategies is to generate running time models, using before and after data while isolating the impacts of each strategy through the use of dummy variables. Synergies can also be measured through a single dummy variable comparing the before to the after time period. Running time models that use archived AVL/APC data are well known in the transit literature, and have been used by several researchers (El-Geneidy et al., 2006; Kimpel, 2001; Kimpel et al., 2005).

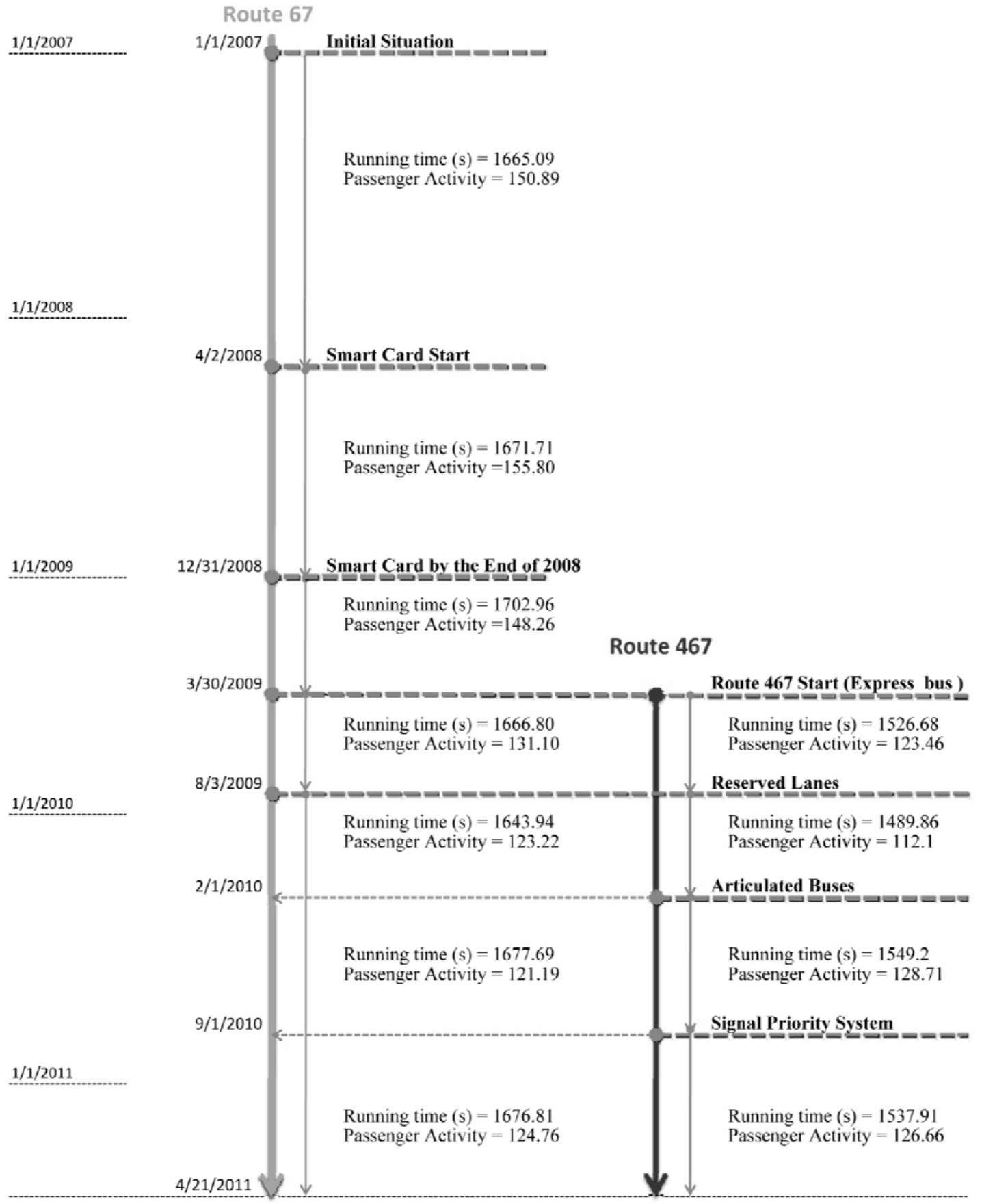

Figure 1: Time line of changes in bus service along Route Saint Michel 
To a great extent, the majority of literature covering transit agencies improvement strategies has been done by investigating the effects of one or two strategies meant to improve the service. Several studies agreed that limited-stop bus service, reserved bus lane, and TSP decrease running time (Kimpel et al., 2005; Surprenant-Legault and El-Geneidy, 2011; Tétreault and El-Geneidy, 2010), while articulated buses and smart card systems increase running time (El-Geneidy and Surprenant-Legault, 2010; El-Geneidy and Vijayakumar, 2011; SurprenantLegault and El-Geneidy, 2011). While the following section will review the literature covering these strategies and their expected impacts, none of these studies provide a comprehensive analysis that measure the impacts of implementing these set of measures on bus running time for two parallel high-frequency routes (less than 10 minutes) sharing the same corridor.

Limited stop (express) service is considered one of the most effective strategies for decreasing running time (Ercolano, 1984; Furth and Day, 1985). Limited stop buses serve only a few stops along a route, while a parallel regular route serves all stops including the limited and intermediate stops. A few studies were published estimating or reporting the savings due to the implementation of this service (Diaz and Hinebaugh, 2009; El-Geneidy and Surprenant-Legault, 2010; Tétreault and El-Geneidy, 2010). The savings vary depending on the number of stops included in the express service as well as the demand for this new service. Also a small number of studies concentrated on riders satisfaction and perception of time savings after the implementation of service (Conlon et al., 2001; Furth and Day, 1985). The majority of research investigating the effects of reserved bus lanes on running time used simulation or has been derived from descriptive statistics (Shalaby, 1999; Tanaboriboon and Toonim, 1983; Thamizh Arasan and Vedagiri, 2010). One recent study provides more accurate estimations using before and after AVL/APC data to isolate the effect of reserved lane. This study estimated that the time savings due to the implementation of reserved lane ranged between $1.2 \%$ and $2.3 \%$ of total running time (Surprenant-Legault and El-Geneidy, 2011). Moreover, smart cards are used by transit operators to minimize fare fraud and pilfering (Corinne, 2008), to reduce operating and maintenance costs associated with magnetic strip card readers (Attoh-Okine and Shen, 1995), and to increase passenger satisfaction (Multisystems et al., 2003; Société de transport de Montréal, 2009). The most common smart card used in public transit is the contactless card, which is equipped with a microprocessor and operated by a reader through a radio frequency (Holcombe, 2005; Multisystems et al., 2003). According to previous research, the use of smart card have had a general negative effect increasing running time compared to using flash passes (El-Geneidy and Surprenant-Legault, 2010; Kittelson \& Associates et al., 2003; SurprenantLegault and El-Geneidy, 2011).

Articulated buses can be found on heavily used routes (Jarzab et al., 2002; Levinson et al., 2002) as they can carry more passengers than regular buses during one trip and have higher loading (boarding and alighting passengers) speeds (Kaneko et al., 2006). Nevertheless, many transit agencies found that the maintenance cost and fuel consumption of articulated buses was higher compared to regular buses, while acceleration and performance were much lower (Hemily and King, 2008). The use of articulated buses along a transit corridor is expected to have a mixed effect on running time. The first is a negative effect increasing running time due to the acceleration, deceleration and maneuvering time. The second is a positive effect decreasing running time due to the decline in the time associated to passenger activity (El-Geneidy and Vijayakumar, 2011). In addition, TSP is a complex element, which involves traffic signal systems, transit vehicle detection systems and communication technologies. Evaluation of TSP is 
often done using simulation techniques (Balke et al., 2000; Dion et al., 2004; Shalaby et al., 2003; Smith et al., 2005) as well. Although the majority of TSP studies show improvements in running time, service reliability and efficiency the practice shows that significant differences are the exception rather than the rule (King County Department of Transportation, 2002). This is confirmed by a study developed in 2005 using archived AVL/APC data collected before and after TSP implementation (Kimpel et al., 2005). The study confirmed that TSP benefits are not consistent across routes and time periods.

\section{METHODOLOGY}

The data used in this study comes from STM's archived AVL/APC systems. The archived AVL/APC data is widely recognized in transit research as a rich source of information for planning and operational improvements (Dueker et al., 2004; El-Geneidy et al., 2006). However, only 18\% of STM's buses (306 out of 1680 buses) are outfitted with AVL/APC. STM assigns these buses to different routes in order to obtain a sample of the network operational information. The obtained data for Routes 67 and 467 led to a sample of 62,000 trip level observations (around 2,270,000 stop level observations) for both routes. The data was collected between January $1^{\text {st }}, 2007$ and April $21^{\text {st }}$, 2011. This trip level data were cleaned by removing incomplete trips, holidays, weekend trips, system recording errors, trips with insufficient passenger activity (less than 6 boarding or alighting passengers), and trips during construction periods, deleting around 1027 trips. After this data cleaning process, two datasets were constructed. The first include records from January to April 2007 and 2011, which contains 6,478 trips. The second dataset contains 60,973 complete trips between January $1^{\text {st }}, 2007$ and April 21 $1^{\text {st }}, 2011$.

Figure 2 shows Route 467 and 67 as well as the analyzed segment along the routes. They run north-south (about $9.4 \mathrm{~km}, 5.8$ mile) from boulevard Henri-Bourassa in the north to Rue Hochelaga in the south along boulevard Saint-Michel, crossing through five boroughs of the City of Montréal. Both Routes 67 and 467 share the same space and connect two metro stations, Joliette metro station, at the end of the southern direction, and Saint-Michel station, at its midway point. The route's main corridor (boulevard Saint-Michel) consists of three lanes in each direction with no median island for the majority of the corridor. Route 67 average stop spacing is 241 and 255 meter southbound and northbound direction, respectively, while Route 467 is 611 and 623 meter southbound and northbound direction, respectively. As seen in Figure 1, the segment analyzed in this paper stretches between boulevard Saint-Joseph in the south and rue Fleury in the north (6.82 km; 4.24 mile). This segment was chosen primarily because it did not experience any changes in term of number of assigned stops or locations along boulevard SaintMichel during the study period (2007-2011). A total of 28 signalized intersections are functioning along the analyzed segment. All traffic signals are equipped with TSP functionality. The TSP system operates when a bus that is equipped with this technology is detected by the traffic signal while approaching an intersection, either the green lights is extended or a priority is activated, giving the bus a head start over motorists (Société de Transport de Montréal, 2011). Only 2,957 trips were made by buses equipped with TSP during the study period. Routes 467 are served by both articulated buses and regular low floor buses. Around 9,864 of the total trips were made by articulated buses.

In this research we will be concentrating on two statistical models to capture and isolate the effects of the improvement strategies made by STM during the study period. Table 2 includes a list of variables to be incorporated in the statistical analysis. According to previous studies, the factors affecting running time include passenger activity, passenger activity associated with 
articulated buses, number of stops made, time of the day, delays at the beginning of a trip, bus type and weather conditions.

The first running time model is a general model that captures the overall impact of all changes made by STM during the study period. AVL/APC data from January 2007 to April 2007 is included as well as data from January 2011 to April 2011. The key variable in this model is Y2011, a dummy variable that will distinguish between the two. This variable will capture the impacts of all the changes made on route 67 . A positive value will indicate an increase in the overall running time, whereas a negative one indicates a decline and improvements in running time along route 67. Since route 467 did not exist during the 2007 period, the Y2011 variable need to be combined with the 467 dummy to understand the level of improvements that route 467 brought to this corridor. The model specification is:

1. Running time $=f($ Maximum passenger load, Actual stops made, Total passenger activity (boardings and alightings), Precip rain ( $\mathrm{mm}$ ), Snow on the ground (cm), Route 467, Northbound trip, Delay at the start of the trip, AM Peak trip, PM Peak trip, Night trip, Midnight and early morning trip, Y2011)

The second running time model contains dummy variables to control for the implementation of a smart card system, reserved lanes, limited-stop service, articulated buses and TSP. A dummy, Smart Card Start, distinguishes the trips made after the introduction of a new smart card payment system. According to STM, by the end of 2008, about a half million smart cards were in circulation (Société de transport de Montréal, 2009), therefore the study includes another variable called 'smart card by the end 2008' to distinguish the trips made after this date, in order to demonstrate the real effect of the implementation of smart card system. A second dummy variable, Reserved Lane, included distinguishing trips made after the reserved lane's implementation. Reserved lanes are operated on weekdays between 6:30 A.M. and 9:00 A.M. southbound and between 2:30 P.M. and 6:30 P.M. northbound. A third dummy variable, Articulated buses, characterizes articulated buses in operation along Route 467. A dummy variable to distinguish all the trips made after this date called 'After articulated buses date' is included. This dummy will help in showing the effect of articulated buses on other buses running time along the corridor. A dummy variable called 'TSP' is used to distinguish TSP equipped buses from others. It is important to note that all TSP equipped buses are articulated and operating on route 467. Finally, a dummy variable called 'After TSP date'distinguishs all trips made after the implementation of TSP to measure the impact of TSP on unequipped buses. The model specification is:

2. Running time $=f($ Maximum passenger load, Actual stops made, Total passenger activity (boardings and alightings), Articulated passenger activity (boarding and alighting on an articulated bus), Rain (mm), Snow on the ground (cm), Route 467, Northbound trip, Delay at the start of the trip, AM Peak trip, PM Peak trip, Night trip, Midnight and early morning trip, Smart card start, Smart card by the end of 2008, Reserved bus lane in operation, After articulated buses operation date, Articulated buses, After TSP implementation date, TSP equipped buses)

The explanations of each variable used in both models are presented in Table 1. 


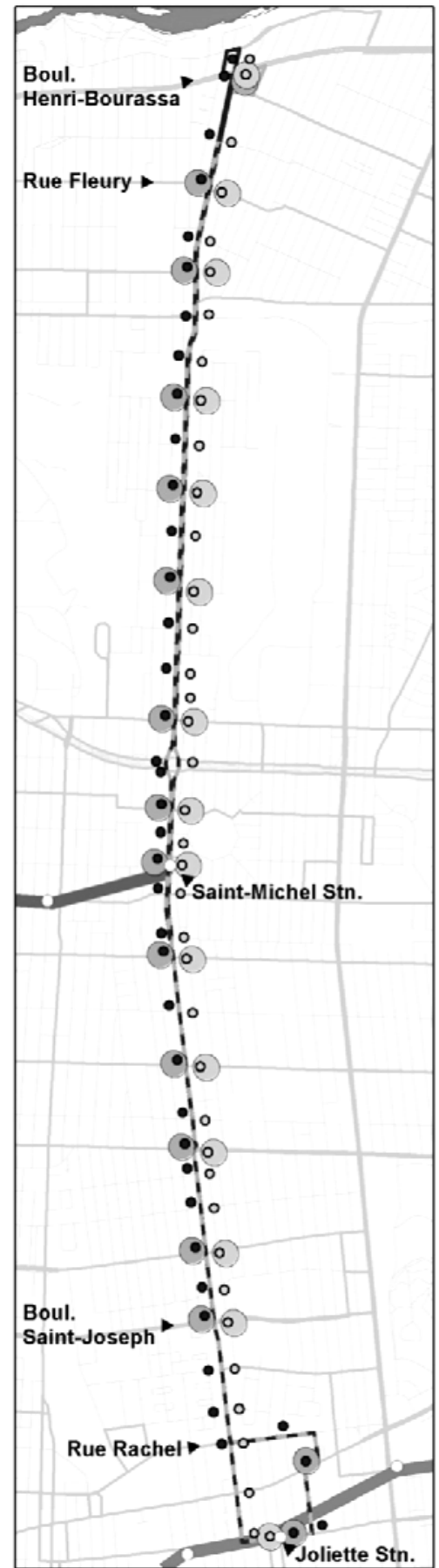

Data Sources: STM \& DMTI
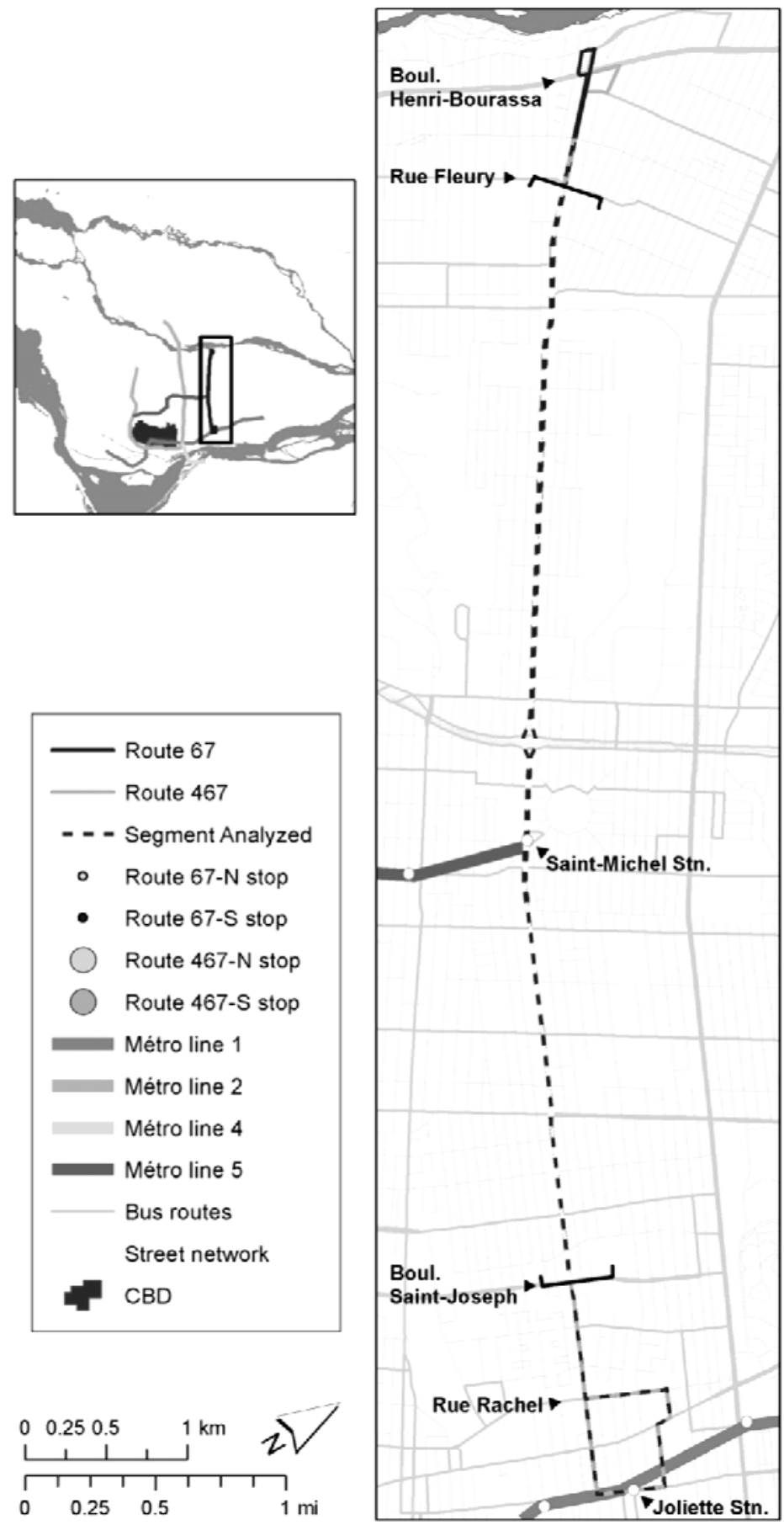

Projection: NAD 1983 MTM 8

Figure 2: Study routes and the analyzed segment 
Table 1: Description of variables used in the regression models

\begin{tabular}{|c|c|}
\hline Variable Name & Description \\
\hline Running Time (seconds) & The running time per trip in seconds \\
\hline Y2011 & $\begin{array}{l}\text { A dummy variable that is equal } 1 \text { if the trip took place from January to April, } \\
2011 \text {. When it is equal } 1 \text {, the variable means that the trips made after the } \\
\text { implementation of all measures, a smart card fare collection, limited-stop bus } \\
\text { service, reserved bus lane, articulated buses, and transit signal priority (TSP). }\end{array}$ \\
\hline R467 & A dummy variable that equals 1 if the trip is serving route 467 \\
\hline $\mathrm{N}$ & Dummy variable for northbound trips \\
\hline Total Passenger Activity & The total number of passengers boarding or alighting during a trip. \\
\hline Articulated passenger activity & $\begin{array}{l}\text { The total number of passengers boarding or alighting on an articulated bus } \\
\text { during a trip. }\end{array}$ \\
\hline Maximum Load & The maximum load during a trip. \\
\hline Actual stops made & The number of actual stops that was actually made by bus during a trip \\
\hline Precip (mm) & $\begin{array}{l}\text { The amount of rainfall in millimetres }(1 \mathrm{~mm} \text { of precipitation }=1 \text { litre per square } \\
\text { meter) on the day of the trip. }\end{array}$ \\
\hline Snow $(\mathrm{cm})$ & The amount of snow on the ground in centimeters on the day of the trip \\
\hline Delay at the start (s) & $\begin{array}{l}\text { The delay at the beginning of the route in seconds, which equals the leave time } \\
\text { minus the scheduled time at the first stop }\end{array}$ \\
\hline Delay at the end (s) & $\begin{array}{l}\text { The delay at the end of the route in seconds, which equals the leave time minus } \\
\text { the scheduled time at the last stop }\end{array}$ \\
\hline AM Peak & $\begin{array}{l}\text { A dummy variable that is equal } 1 \text { if the trip took place between 6:30 am to 9:30 } \\
\text { am }\end{array}$ \\
\hline PM Peak & $\begin{array}{l}\text { A dummy variable that is equal } 1 \text { if the trip took place between } 3: 30 \mathrm{pm} \text { and } \\
\text { 6:30 pm }\end{array}$ \\
\hline Night & $\begin{array}{l}\text { A dummy variable that is equal } 1 \text { if the trip took place between } 6: 30 \mathrm{pm} \text { to } \\
12: 00 \mathrm{am}\end{array}$ \\
\hline Midnight & $\begin{array}{l}\text { A dummy variable that is equal } 1 \text { if the trip took place between } 12: 00 \text { am and } \\
6: 30 \mathrm{am}\end{array}$ \\
\hline Smart card start & $\begin{array}{l}\text { A dummy variable that is equal } 1 \text { if the trip took place after the introduction of a } \\
\text { new smart card payment system (named OPUS) on April } 1^{\text {st }}, 2008\end{array}$ \\
\hline Smart card by the end of 2008 & $\begin{array}{l}\text { A dummy variable that is equal } 1 \text { if the trip took place after the wide spreading } \\
\text { of the new smart card payment system (named OPUS) on December } 31^{\mathrm{st}}, 2008\end{array}$ \\
\hline Reserved lane & $\begin{array}{l}\text { Dummy variable that equals } 1 \text { if the trip observed is recorded uses the reserved } \\
\text { bus lanes. When equal 1, the variable means that the trips made after August } 3^{\text {rd }} \text {, } \\
\text { 2009, and between 6:30 A.M. and 9:00 A.M. southbound and between 2:30 } \\
\text { P.M. and 6:30 P.M. northbound when the reserved lane is functioning. }\end{array}$ \\
\hline After articulated buses date & $\begin{array}{l}\text { A dummy variable that equals to one if the trip observed is after the use of } \\
\text { articulated bus service on boulevard Saint-Michel in February } 1^{\text {st }}, 2010 \text {. }\end{array}$ \\
\hline Articulated buses & $\begin{array}{l}\text { A dummy variable that equals } 1 \text { if the trip observed is recorded using an } \\
\text { articulated bus. }\end{array}$ \\
\hline After TSP date & $\begin{array}{l}\text { A dummy variable that equals } 1 \text { if the trip observed is after the use of } \\
\text { TSP equipped buses on boulevard Saint-Michel in September } 1^{\text {st }}, 2010 \text {. }\end{array}$ \\
\hline TSP & $\begin{array}{l}\text { A dummy variable that equals } 1 \text { if the trip observed is recorded uses TSP } \\
\text { equipped buses. }\end{array}$ \\
\hline
\end{tabular}

The second part of the analysis compares the actual running time changes to riders' perceptions. A short field survey (one page include a French and English sections) was carried out by the research team in June 2011 among 354 users at stops serving both routes 67 and 467 .

Passengers were asked which route (Route 67 or 467) do they used most often and how often they used this route. They were also asked to evaluate their travel and waiting time and 
compare it to the period when they started using either route 67 and 467 . The survey requests the riders to report their boarding and alight stations. The survey also asked the riders to report the dates when they started using either route.

\section{ANALYSIS}

\section{DESCRIPTIVE STATISTICS}

Table 2 presents summary statistics for Route 67 and 467. The table compares the following six variables at the trip level of analysis: running time, total trip passenger activity, actual stops made, delay at the start, delay at the end, and trip maximum passenger load. Also in the table, route statistics are differentiated by two periods. Start period which is representing the situation before implementation any measures, from January to April of 2007 for Route 67, and from May to July of 2009 for Route 467. The year 2011 period, from January to April of 2011, represents the route situation after the implementation of studied measures along the routes. Furthermore, Figure 1 presented the averages of bus running time and passenger activity in relation to each strategy that was implemented along Routes 67 and 467.

Table 2: Descriptive Statistics for start period and 2011 period

\begin{tabular}{|c|c|c|c|c|c|c|c|c|}
\hline & \multicolumn{4}{|c|}{ Route 67} & \multicolumn{4}{|c|}{ Route 467} \\
\hline & \multicolumn{2}{|c|}{$\begin{array}{l}\text { Start (from } \\
\text { January to } \\
\text { April 2007) }\end{array}$} & \multicolumn{2}{|c|}{$\begin{array}{l}\text { Year } 2011 \text { (from } \\
\text { January to April } \\
\text { 2011) }\end{array}$} & \multicolumn{2}{|c|}{$\begin{array}{l}\text { Start (from May } \\
\text { to July 2009) }\end{array}$} & \multicolumn{2}{|c|}{$\begin{array}{l}\text { Year } 2011 \text { (from } \\
\text { January to April } \\
\text { 2011) }\end{array}$} \\
\hline & Mean & $\begin{array}{l}\text { Std. } \\
\text { Dev. }\end{array}$ & Mean & $\begin{array}{l}\text { Std. } \\
\text { Dev }\end{array}$ & Mean & $\begin{array}{l}\text { Std. } \\
\text { Dev }\end{array}$ & Mean & $\begin{array}{l}\text { Std. } \\
\text { Dev }\end{array}$ \\
\hline Running Time (s) & 1662.2 & 170.9 & 1688.3 & 198.9 & 1526.7 & 129.4 & 1535.2 & 185.2 \\
\hline Passenger activity & 155.1 & 63.0 & 131.9 & 54.4 & 123.5 & 48.4 & 137.4 & 67.6 \\
\hline Actual stops made & 24.6 & 3.1 & 22.3 & 3.4 & 12.7 & 0.7 & 12.5 & 0.9 \\
\hline Delay at the start (s) & 38.2 & 89.5 & 56.3 & 114.6 & 56.2 & 105.3 & 64.7 & 131.3 \\
\hline Delay at the end (s) & 32.9 & 145.2 & 149.7 & 192.8 & -100.5 & 154.1 & 81.52 & 189.2 \\
\hline Max. passenger load & 43.5 & 15.4 & 37.4 & 13.1 & 39.1 & 13.8 & 44.5 & 20.8 \\
\hline Average speed $(\mathrm{km} / \mathrm{h})$ & 14.8 & & 14.5 & & 16.1 & & 16.0 & \\
\hline Number & 2538 & & 2548 & & 348 & & 2001 & \\
\hline
\end{tabular}

\section{RUNNING TIME MODELS}

Two linear regression models are developed using running time in seconds, between boulevard Saint-joseph and rue Fleury for Routes 67 and 467, as the dependent variable. Table 3 presents the results of these models. The first model, which concentrates on the 2007 and 2011 periods contains 6,478 trips and explains $62 \%$ of the variation in running time.

The key policy variable 'Y2011', which accounts for the difference in the running time between 2007 and 2011 on route 67, has a positive coefficient. This indicates that trips made 
during the after period (January to April 2011) are slower by 56.11 seconds compared to trips made between January and April 2007 while keeping all other variables at their mean values. Although STM has implemented several strategies to improve running time along the corridor such as express bus service, exclusive lane, TSP, the introduction of the smart card system, and the use of articulated buses along this corridor had collectively a greater positive impact on running time (added more time), which will be confirmed in the next model. Regarding the second policy variable ' $R 467$,' it is clear that route 467 , which was not present in 2007 , is faster than route 67 by 134 seconds southbound and by 224 seconds northbound. Although both northbound and southbound trips have the same distance and number of signalized intersections, the difference in running times between the two directions could be explained by traffic conditions. Nevertheless, these savings represent $8.2 \%$ and $13.4 \%$, which is consistent with previous studies (El-Geneidy and Surprenant-Legault, 2010; Surprenant-Legault and El-Geneidy, 2011). Accordingly the actual difference in running time between a bus serving route 67 in 2007 and a bus serving route 467 in 2011 is 78 seconds for southbound and 168 seconds for northbound. This model enables a better understanding of the combined impacts of the operational improvement strategies introduced by STM along the studied routes.

The remaining variables in the models follow the expected sign and power. For every stop made along the routes, 5.03 seconds are added to the running time due to dwell time, acceleration and deceleration at each stop. The total passenger activity (boarding and alighting) increases running time by 1.39 seconds per passenger. For every millimeter of rainfall, running time is expected to increase by 0.79 seconds per trip, while for every centimeter of snow on the ground running time increase by 1.81 seconds per trip. This finding is consistent with previous studies (El-Geneidy and Vijayakumar, 2011; Surprenant-Legault and El-Geneidy, 2011). Buses starting late compared to schedules are generally faster. This is because bus drivers would try to compensate for the delay that they have at start. Running time decreases by 0.22 seconds for every second of delay at the beginning of the route. Trips during PM peak are much longer (49.5 seconds) than midday trips, which is expected due to congestion and the increase in demand. Trips made during AM peak, night, and midnight are faster, by 47.03, 100.47, and 219.16 seconds respectively, compared to midday trips, which is also consistent with previous studies (Tétreault and El-Geneidy, 2010). 
Table 3: Running time Models

\begin{tabular}{|c|c|c|c|c|}
\hline & \multicolumn{2}{|c|}{$\begin{array}{l}2007 \text { data (from January to } \\
\text { April) and } 2011 \text { data (from } \\
\text { January to April) }\end{array}$} & \multicolumn{2}{|c|}{$\begin{array}{l}\text { All data (from January } 2007 \text { to } \\
\text { April 2011) }\end{array}$} \\
\hline & Coefficients & $\mathrm{T}$ & Coefficients & $\mathrm{t}$ \\
\hline Constant & $1425.73 * * *$ & 92.86 & $1395.80 * * *$ & 266.07 \\
\hline Maximum Passenger Load & $-0.40 *$ & -2.03 & $-0.75 * * *$ & -10.00 \\
\hline Actual stops made & $5.03 * * *$ & 7.36 & $5.21^{* * *}$ & 21.38 \\
\hline Total passenger activity & $1.39 * * *$ & 24.31 & $1.56^{* * *}$ & 71.86 \\
\hline Articulated passenger activity & & & $-0.21 * * *$ & -7.78 \\
\hline Precip & $0.79 * *$ & 2.54 & $0.52 * * *$ & 6.60 \\
\hline Snow & $1.81 * * *$ & 9.57 & $1.07^{* * *}$ & 13.95 \\
\hline R467 & $-134.32 * * *$ & -15.75 & $-123.75^{* * *}$ & -35.57 \\
\hline $\mathrm{N}$ & $-89.79 * * *$ & -29.16 & $-60.22 * * *$ & -56.58 \\
\hline Delay at the start (s) & $-0.22 * * *$ & -15.95 & $-0.17 * * *$ & -35.11 \\
\hline AM Peak & $-47.03 * * *$ & -10.79 & $-33.59 * * *$ & -21.65 \\
\hline PM Peak & $49.54 * * *$ & 11.61 & $60.14^{* * *}$ & 38.93 \\
\hline Night & $-100.47 * * *$ & -20.99 & $-99.94 * * *$ & -62.21 \\
\hline Midnight & $-219.16 * * *$ & -30.63 & $-212.50 * * *$ & -87.35 \\
\hline Y2011 & $56.21_{* * *}$ & 14.10 & & \\
\hline Smart card start & & & $5.83^{* * *}$ & 3.15 \\
\hline Smart card by the end of 2008 & & & $46.81 * * *$ & 24.79 \\
\hline Reserved lane & & & $-35.26 * * *$ & -20.08 \\
\hline After articulated buses date & & & $26.80 * * *$ & 14.68 \\
\hline Articulated buses & & & $43.62 * * *$ & 10.24 \\
\hline After TSP date & & & $-4.76^{* *}$ & -2.64 \\
\hline TSP & & & $-13.56^{* * *}$ & -4.37 \\
\hline $\bar{N}$ & 6,478 & & 60,973 & \\
\hline R2 & 0.62 & & 0.59 & \\
\hline
\end{tabular}

*** Significant at $99.9 \% * *$ Significant at $99 \% *$ Significant at $95 \%$

Regarding the second detailed running time model, it is clear that the model follows the same signs and magnitude as the previous model. The introduction of the smart card (OPUS) fare collection system on buses on April $1^{\text {st }}, 2008$ increased the trips running time on route 67 by 5.83 seconds. By the end of 2008, this value increased by 46.8 seconds to reach 52.61 seconds. This increase is related to the growth in the number of smart card users compared to using traditional flash passes, a finding that is consistent with previous work (El-Geneidy and Surprenant-Legault, 2010). As would be expected, the implementation of the reserved bus lanes along boulevard 
Saint Michel decreased running time by 35.26 seconds on average. This saving in running time due to the use of reserved lanes is considered small. One explanation for this is the effect of cars waiting in this lane to turn right at a traffic light, as cars cannot turn right on red lights on the island of Montréal (Surprenant-Legault and El-Geneidy, 2011).

The introduction of articulated buses along the corridor increased the running time by 26.80 seconds along the corridor. Although articulated buses run only on Route 467, this increase is due to the high-frequency of service along the two routes. As in many cases buses are directly behind each other, since the average headway for Route 467 and Route 67 is only 7 minutes during the peak hours. The use of an articulated bus adds 70.4 seconds along Route 467, which is the combined effect of the 43.62 seconds associated with the use of an articulated bus and 26.80 seconds associated to the time period of implementing this service. However, this value does not explain the true effect of an articulated bus on the running time. Operation of an articulated bus has a mixed effect on running time, increasing time associated with acceleration, deceleration and merging with traffic, and decreasing time associated with passenger activity. Hence, the model includes a 'articulated passenger activity' variable which captures the savings in dwell time by 0.2 second per passenger (and the average trip passenger activity is 126 passengers), indicating a savings of 26.3 seconds in dwell time. Accordingly, operating an articulated bus adds 44.1 seconds on running time, which is consistent with previous studies (ElGeneidy and Vijayakumar, 2011). Furthermore, since the majority of operated buses along Route 467 are articulated, the difference on Route 467 saving between the two regression models can be also explained.

Around 50 operated articulated buses along Route 467 are outfitted with a TSP system (Société de Transport de Montréal, 2011). After the introduction of these buses on September $1^{\text {st }}$, 2010, the total travel time decreased by 4.76 seconds $(0.3 \%)$ for all buses serving the corridor, even if they were not equipped with TSP. For TSP-equipped buses, the total running time savings reached 18.32 seconds (1.2\%). According to previous work in transit literature, TSP benefits are not consistent across routes and time periods. Nevertheless, it is possible that the benefits of the TSP system are mitigated because of the corridor's physical factors and system design (e.g., AVL and signal controller logic), and operational factors, such as excess traffic congestion and delay-causing events. Therefore, a more detailed study concerning TSP operation along the corridor is required in order to maximize the benefits.

Using the second running time model coefficients, it is possible to estimate the changes in running time by conducting a sensitivity analysis that predicts the changes on average running time for each route while keeping all variables constant at their mean values. This sensitivity analysis enables a better understanding of the synergies impacts of each change in the operational environment. Table 4 presents the estimated running times and the percentage of change compared to Route 67 initial situation. As seen in this table, the introduction of OPUS increased running time along Route 67 by 3\% on average compared to Route 67 initial situation. Running time in general declined by $0.3 \%$ along Route 67 after the implementation of the limited-stop service (Route 467), mainly due to a decline in the number of passengers using Route 67 . For route 467 , the running time saving was around $11 \%$ on average compared to Route 67 initial situation, this drop in running time is related to the decline in the number of stops and to the number of passengers using the route per trip. Hence, the reserved bus lanes operated only on northbound PM peak and southbound AM peak, the savings along Route 67 and 467 trips 
using these lanes were 1.7\% and 13\% compared to Route 67 initial situation, respectively. On the contrary, trips running on northbound AM peak and southbound pm peak had not benefits from the reserved lanes as they are implemented on the other side of the corridor.

After using articulated buses along route 467 running times have declined by $10.2 \%$ and $10.5 \%$ for those buses using the reserve lanes, and by $8.2 \%$ and $8.7 \%$ for other trips not benefiting from the reserved lanes. The operation of articulated buses along Route 467 affected Route 67 performance, increasing running time by $0.2 \%$ and $0.4 \%$ on average for those trips using the reserved lanes and by $2.2 \%$ and $2.4 \%$ for other trips. The installation of a TSP system on articulated buses decreased running time by $11.3 \%$ and $11.5 \%$ on average compared to Route 67 initial situation for buses using reserved lanes, and by $9.3 \%$ and $9.8 \%$ for other buses not using the reserved lanes. Also for Route 67, the running time decreased by $0.1 \%$ for buses using reserved lanes, and by $2 \%$ for other buses. Finally, it is clear that collectively after the implementation of all measures, Route 467 is faster by $10.2 \%$ on average, while Route 67 is slower by $1 \%$ on average, compared to Route 67 in the initial situation.

Table 4: Estimated Running time in seconds and the percentage of change* comparing to Route 67 initial situations

\begin{tabular}{|c|c|c|c|c|c|c|}
\hline \multicolumn{7}{|l|}{ Route 467} \\
\hline Scenario & & & $\begin{array}{c}\text { Initial } \\
\text { Situation }\end{array}$ & $\begin{array}{c}\text { Reserved } \\
\text { lanes }\end{array}$ & $\begin{array}{l}\text { Articulated } \\
\text { Buses }\end{array}$ & TSP \\
\hline North AM Peak & & & $1440(-11.5 \%)$ & & 1486(-8.7\%) & 1467(-9.8\%) \\
\hline North PM Peak & & & $1534(-10.8 \%)$ & $1498(-12.9 \%)$ & $1544(-10.2 \%)$ & 1526(-11.3\%) \\
\hline South AM Peak & & & $1500(-11.1 \%)$ & $1465(-13.2 \%)$ & 1511(-10.5\%) & 1492(-11.5\%) \\
\hline South PM Peak & & & $1588(-10.8 \%)$ & & $1634(-8.2 \%)$ & 1616(-9.3\%) \\
\hline \multicolumn{7}{|l|}{ Route 67} \\
\hline Scenario & $\begin{array}{c}\text { Initial } \\
\text { situation }\end{array}$ & OPUS & $\begin{array}{c}\text { After the } \\
\text { limited-stop } \\
\text { service }\end{array}$ & $\begin{array}{l}\text { Reserved } \\
\text { lanes }\end{array}$ & $\begin{array}{c}\text { After } \\
\text { Articulated } \\
\text { date }\end{array}$ & After TSP date \\
\hline North AM Peak & 1627 & 1677(3.1\%) & 1632(0.3\%) & & 1665 (2.4\%) & 1661 (2.1\%) \\
\hline North PM Peak & 1720 & $1770(2.9 \%)$ & $1725(0.3 \%)$ & $1690(-1.7 \%)$ & $1724(0.2 \%)$ & 1719 (-0.1\%) \\
\hline South AM Peak & 1687 & $1737(3.0 \%)$ & $1692(0.3 \%)$ & $1657(-1.8 \%)$ & 1694 (0.4\%) & $1686(-0.1 \%)$ \\
\hline South PM Peak & 1781 & $1831(2.8 \%)$ & $1787(0.4 \%)$ & & $1819(2.2 \%)$ & 1815 (1.9\%) \\
\hline
\end{tabular}

*Change is indicated between brackets

To summarize, the various measures used by STM can divided into two groups. The first group of implemented measures decreases running time along the analyzed corridor. These measures include limited-stop bus service (10.8\%), reserved bus lane (2.2\%), and operation of TSP (1.2\%). Meanwhile, the second group increases running time. These measures include implementation of a smart card system (3\%) and operation of articulated buses (2.8\%). It is also important to note that a spillover effect is present when it comes to using TSP and articulated buses, where non-articulated buses experience a decline in running time when operating parallel 
to articulated buses. In addition, non-TSP equipped buses experience savings by running parallel to TSP equipped buses.

\section{SURVEY ANALYSIS}

With credit to these improvements in service, the STM observed an 8\% increase (around 3000 passengers) in total daily ridership on boulevard Saint-Michel between January 2007 and 2011. Therefore, an evaluation of customer satisfaction and perception of time savings after the implementation of these strategies is necessary.

A survey was carried out in June 2011 among 354 users of routes 67 and 467 at 5 northbound stops and 7 southbound stops used by both routes. This sample size at the $95 \%$ confidence level is representing a confidence interval of $5.2 \%$ of the average daily ridership users' opinions along the corridor. The answers revealed that $51.7 \%$ of the respondents used route 467 most often compared to $29.4 \%$ for route 67 , while $18.9 \%$ of the respondents indicated that they used both routes equally. The survey found that around $28.8 \%$ of the respondents changed their usual stop, the nearest to their origin location, to use Route 467. In other words riders are walking longer distances to use the faster service. Around $63.3 \%$ of the respondents indicated that they used Route 67 and/or Route 467 almost 5 days a week or more, while 25.7\% and $11 \%$ indicated that they used these routes either 2 to 4 days a week or one day a week or less, respectively. Around 52.8\% of Route 67 passengers indicated that they were using this route before the implementation of OPUS smart card. Meanwhile, around 53.1\% of Route 467 passengers indicated that they shift to use this route when it started in 2009 or they are new users of the 467 service. Riders were asked to indicate their boarding and alighting stops as well as the date when they started using this route. Each surveyed rider was asked to indicate the average amount of time savings that he/she felt over time. Table 5 presents a summary of the survey findings in term of perceptions of running time savings. Confidence intervals for these questions vary between $7.2 \%$ to $9.2 \%$ at $95 \%$ confidence level. In this table, the perceived change in waiting and travel time is differentiated by route number.

As seen in table 5 , while $49.2 \%$ of riders noticed that their travel time decreased compared to when they started using the bus services along Route 467 , only $7.1 \%$ felt a longer commute, and $43.7 \%$ did not notice a change. For route 67 , the perception of decrease in their travel time reached $54.8 \%$, with only $9.6 \%$ who were seeing an increase in their travel time, and $35.6 \%$ did not see any change. Meanwhile, $55.2 \%$ of Route 67 or/and Route 467 users, whom are using the both routes according to the availability of buses or/and equally, felt the their travel time decreased compared to when they started using the bus services along the corridor, while $7.5 \%$ felt a longer commute, and $37.3 \%$ did not notice a change. 
Table 5: Survey findings summary

Travel time

\begin{tabular}{lccc}
\hline Perception & Route 467 & Route 67 & Route 67 \&467 \\
\hline Decrease in time & $49.2 \%$ & $54.8 \%$ & $55.2 \%$ \\
Increase in time & $7.1 \%$ & $9.6 \%$ & $7.5 \%$ \\
No change & $43.7 \%$ & $35.6 \%$ & $37.3 \%$ \\
\hline Number of observations & 183 & 109 & 67 \\
\hline \% of the sample & $51.7 \%$ & $29.4 \%$ & $18.9 \%$ \\
\hline confidence interval* & $7.2 \%$ & $8.5 \%$ & $9.2 \%$
\end{tabular}

*The confidence interval (also called margin of error) at the 95\% confidence level

In addition to the amount of time savings, the survey asked the riders to identify the bus stops that they use for boarding and alighting as well as the time when they started using either rout. This information was compared for every rider with the average travel time changes using archived AVL data. Then, a difference in means t-test was used to compare perceptions to the actual travel time changes. Therefore, this test had done only for Route 467 and 67 users.

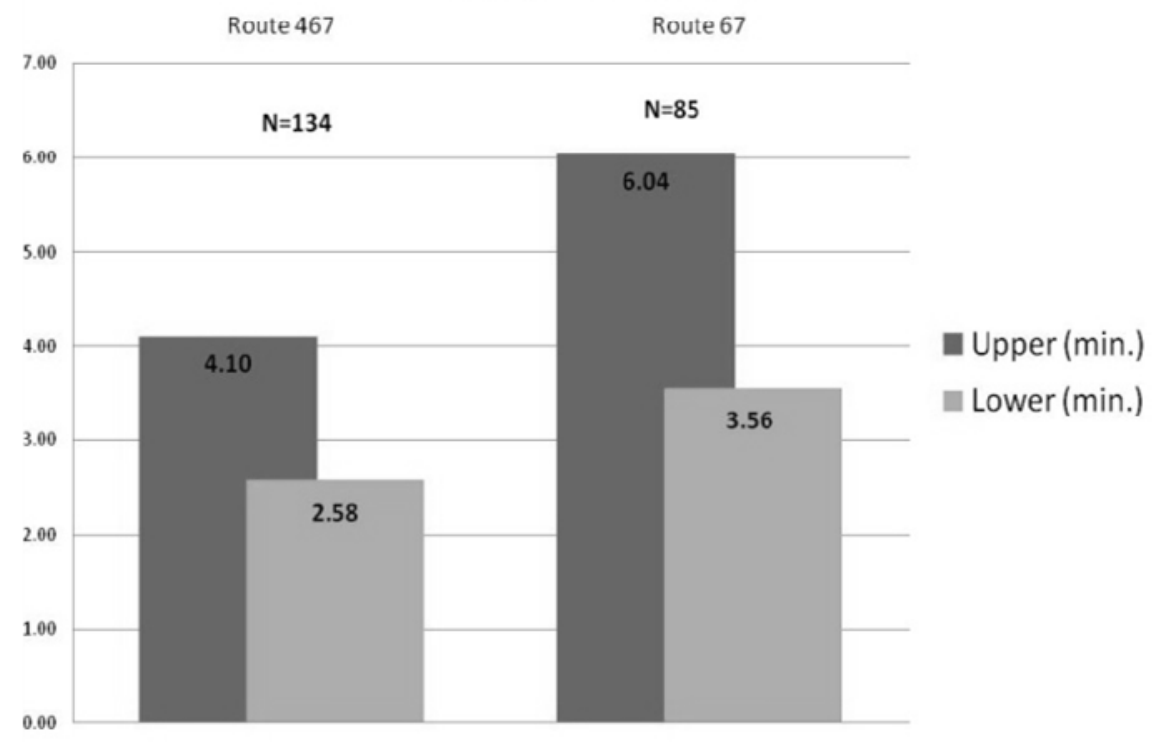

Figure 2: Users paired differences using means t-test

Figure 2 shows the users paired difference according to the route used. For route 467 riders, a statistically significant difference exists between their estimates and the actual savings when they started using the same route. Users over estimated their travel time savings within a range of 2.5 to 4.1 minutes. This amount of time is presenting around $9.6 \%$ to $16.1 \%$ of 
Route 467 average running time in 2009. For route 67, there was a statistically significant difference between the perception of change and actual change. Users over estimated their travel time savings by 3.5 to 6.0 minutes. This amount of time represents around $12.6 \%$ to $21.7 \%$ of Route 67 running time during the initial situation in 2007. This indicates that, generally, the studied set of measures along the Boulevard Saint-Michel corridor has a positive effect on riders' perceptions. Although the majority of these measures are implemented for Route 467, starting from the implementation of the 467 service itself, reserved bus lanes, introduction of articulated buses, and TSP systems, Route 67 users are feeling more time savings than Route 467 users. One explanation of this difference is that a large percentage of Route 67 passengers have been using the service before 2008, and they have witnessed all the measures that were implemented along the corridor.

\section{CONCLUSION}

The main objective of this article was to evaluate the impact of a combination of measures implemented along boulevard Saint-Michel in Montréal, Canada, on bus running time and how these measures may function together. These measures, in chronological order, are the implementation of a smart card fare collection system ('OPUS'), limited-stop bus service (Route 467), reserved bus lanes, introduction of articulated buses, and TSP systems. After the implementation of these measures, the analysis indicates that the limited-stop bus service (Route 467) provides a faster service by $10.5 \%$ on average, while the regular route (Route 67 ) is slower by $1 \%$ on average compared to the initial situation. A $10 \%$ decline in running time per trip can lead to substantial operation savings. In other words, the operating costs associated to 10 trips can be saved in a corridor that has 100 trips per day, where such strategies are implemented. These numbers could be more if some of the other measures did not take place along the studied corridor, like the smart card implementation and the use of articulated buses. The introduction of smart card system and the use of articulated buses had a larger negative (increasing running time) impact than the positive ones (decreasing running time) associated with the implementation of exclusive lane, faster passenger activity along articulated buses, and TSP. For articulated buses, boardings are limited to the front door and only allowed from the back door when the bus is overcrowded, due to the fare collection procedures. Therefore, moving fare collection off the articulated buses offers the greatest potential to use all doors in order to maximize their benefits, particularly at high passenger activity stops like metro stations, such as Saint-Michel Metro stop. For reserved lanes and TSP, Montreal has a no turn on red policy which affects the cue of cars in front of the bus, though this can be partially addressed by locating stops on the far side. It is important to note that a negative spillover effect was present due to the presence of articulated buses in the corridor which caused delays for other buses. Therefore, mixing between articulated buses and regular ones is not recommended in order to avoid such an effect in the future. Meanwhile, TSP equipped buses had a positive impact on non-TSP equipped buses leading to time savings for these buses. It is important to note that the measures that lead to an increase in running time are generally known to be well received by customers. Benefits do exist from measures like implementing articulated buses, since they do lead to less crowdness along buses. Meanwhile smart card systems are known for their benefits to the agencies in reducing fraud. 
The second objective of this article was to quantify to what extent users have perceived STM's implemented strategies and their effects on their travel time. Generally, users perceived a decrease in their travel time. While there was no actual saving in buses running time, users over estimated their travel time savings within a range of 2.5 to 6.0 minutes. This generally indicates that passengers have a positive attitude towards the improvements in service and over estimate them.

Finally, this article studied the effects of a combination of measures on the buses running time for two high frequency routes sharing the same corridor. Therefore, it is recommended to expand this study and investigate the effects of these measures on the variability of service and actual headway changes. Since not all STM buses are equipped with APC and AVL systems, it is not possible to do that with the current data used in this study. Also, due to the small effects of TSP system on the running time along the corridor, a more detailed study concerning the factor affecting TSP operation and programming along the corridor is required in order to maximize the benefits of the system.

\section{ACKNOWLEDGEMENTS}

We would like to acknowledge the Société de transport de Montréal (STM) for partially funding this research and for providing the data used in the project. Special thanks to Michel Tremblay, Jocelyn Grondines and Sébastien Gagné for their feedback and support during this project. The authors would like to thank Vincent Chakour and Anais Mathez for their help in proof reading the article. This research was funded in part by Natural Sciences and Engineering Research Council of Canada-collaborative research and development (NSERC-CRD) program. 


\section{REFERENCES}

Abkowitz, M., Engelstein, I. (1983) Factors affecting running time on transit routes.

Transportation Research Part A 17, 107-113.

Attoh-Okine, N., Shen, L. (1995) Security issues of emerging smart cards fare collection application in mass transit. Proceedings of Vehicle Navigation and Information Systems Conference, 1995. Proceedings. In conjunction with the Pacific Rim TransTech Conference. 6th International VNIS. 'A Ride into the Future', pp. 523-526.

Balke, K., Dudek, C., Urbanik, T. (2000) Development and evaluation of intelligent bus priority Concept. Transportation Research Record 1727, 12-19.

Conlon, M., Foote, P., O'Malley, K., Stuart, D. (2001) Successful arterial street limited-stop express bus service in Chicago. Transportation Research Record 1760, 74-80.

Corinne, S. (2008) Smart transit cards come to Montreal, Quebec. CBC News, Montreal. (2009) Characteristics of bus rapid transit for decision-making. Washington, D.C., USA. Dion, F., Rakha, H., Zhang, Y. (2004) Evaluation of potential transit signal priority benefits along a fixed-time signalized arterial. Journal of Transportation Engineering 130 (3), 294-303. Dueker, K.J., Kimpel, T.J., Strathman, J.G., Callas, S. (2004) Determinants of bus dwell time. Journal of Public Transportation 7, 21-40.

El-Geneidy, A., Strathman, J., Kimpel, T., Crout, D. (2006) The effects of bus stop consolidation on passenger activity and transit operations. Transportation Research Record 1971, 32-41. El-Geneidy, A., Surprenant-Legault, J. (2010) Limited-stop bus service: An evaluation of an implementation strategy. Public Transport: Planning and Operation 2, 291-306.

El-Geneidy, A., Vijayakumar, N. (2011) The effects of articulated buses on dwell and running times. Journal of Public Transportation 14, 63-86.

Ercolano, J.M. (1984) Limited-Stop Bus Operations: An Evaluation. Transportation Research Record 994, 24-29.

Furth, P., Day, B. (1985) Transit routing and scheduling strategies for heavy demand corridors. Transportation Research Record 1011, 23-26.

Transportation Research Board (2008) TCRP Synthesis 75: Uses of higher capacity buses in transit service. Washington, D.C.

Hensher, D.A., Stopher, P., Bullock, P. (2003) Service quality-developing a service quality index in the provision of commercial bus contracts. Transportation Research Part A 37, 499-517.

Holcombe, B. (2005) Government smart card handbook. U.S. General Services Administration, Washington.

Jarzab, J., Lightbody, J., Maeda, E. (2002) Characteristics of bus rapid transit projects: An overview. Journal of Public Transportation 5, 31-46.

Kaneko, T., Iiuzuka, H., Kageyama, I. (2006) Steering control for advanced guideway bus system with all-wheel steering system. Vehicle System Dynamics 44, 741-749.

Kimpel, T. (2001) Time point-level analysis of transit service reliability and passenger demand. Doctor of Philosophy in Urban Studies, Portland State University.

Kimpel, T., Strathman, J., Bertini, R., Bender, P., Callas, S. (2005) Analysis of transit signal priority using archived TriMet bus dispatch system data. Transportation Research Record, 156166.

King County Department of Transportation (2002) An Evaluation of transit signal priority in Aurora Avenue North, transit speed and reliability program. Seattle, WA.

TRB Transportation Research Board (2003) Transit Capacity and Quality of Service Manual. Washington D.C., USA. 
Levinson, H. (1983) Analyzing transit travel time performance. Transportation Research Record 915, 1-6.

Levinson, H., Zimmerman, S., Clinger, J. (2002) Bus rapid transit: An overview. Journal of Public Transportation 5, 1-29.

Transportation Research Board (2003) Fare policies, structures and technologies: Update Washington.

Murray, A., Wu, X. (2003) Accessibility tradeoffs in public transit planning. Journal of Geographical Systems 5, 93-107.

Shalaby, A. (1999) Simulating performance impacts of bus lanes and supporting measures. Journal of Transportation Engineering 125, 390-397.

Shalaby, A., Abdulhai, B., Lee, J. (2003) Assessment of streetcar transit signal priority options using microsimulation modeling. Canadian Journal of Civil Engineering 30(6), 1000-1009. ITS America (2005) Transit signal priority (TSP): A planning and implementation handbook. Société de transport de Montréal (2009) The STM in 2008 activity report Montreal, Québec. Société de transport de Montréal (2010) On the move 2009 activity report Montreal, Québec. Société de Transport de Montréal (2011) The 467 Express, a taste of tomorrow’s transit. Montréal. Strathman, J.G., Dueker, K.J., Kimpel, T.J., Gerhart, R.L., Turner, K., Taylor, P., Callas, S., Griffin, D. (2000) Service reliability impacts of computer-aided dispatching and automatic location technology: A Tri-Met case study. Transportation Quarterly 54, 85-102.

Surprenant-Legault, J., El-Geneidy, A. (2011) Introduction of a reserved bus lane: Impact on bus running time and on-time performance. Transportation Research Record, 10-18.

Tanaboriboon, Y., Toonim, S. (1983) Impact study of bus lanes in Bangkok. Journal of Transportation Engineering 109, 247-255.

Tétreault, P., El-Geneidy, A. (2010) Estimating bus run times for new limited-stop service using archived AVL and APC data. Transportation Research: Part A 44, 390-402.

Thamizh Arasan, V., Vedagiri, P. (2010) Microsimulation study of the effect of exclusive bus lanes on heterogeneous traffic flow. Journal of Urban Planning and Development 136, 50-58. 